\title{
RETRACTED ARTICLE: Droop Control based Approach for Frequency and Voltage in Hybrid AC/DC Microgrid
}

\author{
Salman Salman ${ }^{1}\left[\right.$. Ai Xin ${ }^{2}$
}

Received: 11 February 2020 / Revised: 28 July 2020 / Accepted: 17 August 2020 / Published online: 28 August 2020

(c) The Korean Institute of Electrical Engineers 2020

The authors have retracted this article [1] because figures 8 , $9,10,11$ and 12 have been previously published in [2] and Figures $13,14,15$ and 16 have been previously published in [3]. Additionally, co-author Ai Xin has stated that the manuscript was submitted without his knowledge and approval. Both authors agree to this retraction.

The online version of this article contains the full text of the retracted article as electronic supplementary material.

\section{References}

1. Salman S, Xin A (2020) Droop control based approach for frequency and voltage in hybrid AC/DC microgrid. J Electr Eng Technol. https://doi.org/10.1007/s42835-020-00524-4

2. Malik SM, Sun Y, Ai X, Zhengqi C, Ansari JA (2019) Voltage-frequency droop scheme for standalone hybrid microgrids. In: Proceedings of the 2019 2nd international conference on computing, mathematics and engineering technologies (iCoMET), Sukkur, Pakistan, pp 1-5. https://doi.org/10.1109/ICOMET.2019.86735 28

3. Malik SM, Sun Y, Ai X, Zhengqi C, Ansari JA (2019) Droopbased converter scheme for linking multiple hybrid microgrids. In: Proceedings of the 2019 2nd international conference on computing, mathematics andengineering technologies (iCoMET), Sukkur, Pakistan, , pp 1-5. https://doi.org/10.1109/ICOME T.2019.8673415

Electronic supplementary material The online version of this article (https://doi.org/10.1007/s42835-020-00524-4) contains supplementary material, which is available to authorized users.

Salman Salman

salman.ali1050@gmail.com

1 Dept. of Electrical and Electronic Engineering, North China Electric Power University, Beijing, China

2 State Key Laboratory of Alternate Electrical Power System with Renewable Energy Sources, School of Electrical and Electronic Engineering, North China Electric Power University, Beijing, China
Publisher's Note Springer Nature remains neutral with regard to jurisdictional claims in published maps and institutional affiliations.

Salman Salman received BE degree from Baluchistan University of engineering and technology in electrical engineering; the MS degree from CIIT Islamabad, Pakistan in 2011 and 2015 respectively. He is currently doing $\mathrm{PhD}$ from NCEPU in Major power system. His research interest includes impacts of PV and battery storage in microgrid environment, generalized modeling of EV, PV and battery storage and converters.

Ai Xin was born in January 1964. He obtained his bachelor's degree, master and doctorate from Nanjing Institute of Technology (currently Southeast University), China Electric Power Research Institute and North China Electric Power University, Beijing, China in 1985, 1988 and 1999 respectively. From 1999 to 2001, he conducted research in the China Electric Power Research Institute as a postdoctoral fellow and in the Brunel University of the United Kingdom (August to December of 2003) as a senior research scholar. Currently, he is professor and PhD student supervisor at the School of Electrical \& Electronic Engineering, North China Electric Power University, and superintendent of the Electric Power System Research Institute.

Prof. Ai has published over 150 academic papers, 100 of which have been collected by the two major literature retrieval systems (namely $\mathrm{SCI}$ and $\mathrm{EI}$ ). He has been engaged in many scientific research projects, including the "Power Quality Analysis and Control of Micro-grid and Distribution System Including Micro-grid (2009CB219706)" as a subproject under the National Program on Key Basic Research Project of China (973 Program), the "Future Grid Pattern and Concept Design", the "Analysis and Research of Power Consumption Behavior Patterns and Electricity Demand Response based on Electricity Information Acquisition Data", the "Study on Wide Area Source and Load Interactive Peak Load Regulation Mode and Scheduling Assistance Decisionmaking Program", the "Study on Impact of Access of Micro-grid from Intelligent Communities on the Grid" and the "Study on Applications of Key Technologies for Micro-grid Control and Economic Operation". Email: aixin@ncepu.edu.cn; tel:+86 13501121641. 